GU J Sci, Part C, 7(1): 236-244 (2019)

Gazi Üniversitesi
Fen Bilimleri Dergisi
PART C: TASARIM VE TEKNOLOJI
http://dergipark.gov.tr/gujsc

\title{
Topoloji Optimizasyonu Yapılmış Parçaların 3B Yazıcılar ile Doğrudan Üretilmesi
}

\author{
Ulaş YAMAN \\ Orta Doğu Teknik Üniversitesi, Mühendislik Fakültesi, Makina Mühendisliği Bölümü, 06800, Çankaya/ANKARA
}

\begin{abstract}
$\underline{\text { Öz }}$
Makale Bilgisi

Basvuru: 02/12/2018

Düzeltme: 28/01/2019

Kabul: 06/02/2019

\section{Anahtar Kelimeler}

Eklemeli imalat

Topoloji optimizasyonu FDM

Doğrudan dilimleme

Bu çalışma çerçevesinde geliştirilen yöntem ile birlikte tasarım ve üretim akışına verilen mekanik parçaların topoloji optimizasyonu yapılmakta ve eklemeli imalat yöntemlerinden Eriyik Yığma Modellemeyi kullanan 3 boyutlu yazıcılarda doğrudan üretilebilmeleri için makine komutları üretilmektedir. Eklemeli imalat yöntemlerinin yaygınlaşmasıyla birlikte topoloji optimizasyonu yöntemlerinin uygulanabilirliği ortaya çıkmıştır. Çalışmada kullanılan Eriyik Yığma Modelleme yöntemi karışı geometriye sahip parçaların üretimi için ilk akla gelen yöntemlerden olmasa da destek malzemesi konusundaki gelişmelerle birlikte daha da sıklıkla kullanılacağı öngörülmektedir. Geliştirilen yöntemde öncelikli olarak verilen parçanın tanımlanan koşullara göre topoloji optimizasyonu yapılmakta ve sonrasında parçanın iç yapısı kabuklardan oluşacak şekilde üretim komutları oluşturulmaktadır. Bu işlemler Rhino3D bilgisayar destekli yazılımı ile birlikte çalışan ve algoritma geliştirme ortamı olan Grasshopper3D ile otomatik olarak gerçekleştirilmektedir. Yöntemin geçerliliğini ortaya koymak için farklı yaklaşımlarla üretilmiş olan yalın dayanaklı kirişler yük altında test edilmiştir. Sonuçlara göre önerilen yöntem ile üretilen kirişin ağırlık-mukavemet başarımı diğerlerine göre oldukça iyidir.
\end{abstract}

\section{Keywords}

Additive manufacturing

Topology optimization

FDM

Direct slicing

\section{Fabrication of Topologically Optimized Parts via Direct 3D Printing}

\begin{abstract}
Within the scope of this study, machine codes are generated to fabricate topologically optimized parts directly, conveyed to the design and fabrication pipeline, utilizing 3 dimensional printers employing Fused Deposition Modeling type of additive manufacturing method. As the additive manufacturing industry advanced, topology optimization methods became applicable on the parts. Although Fused Deposition Modeling, which is used in this study, is not one of the popular methods for fabricating complicated parts, it will be utilized more frequently in the near future with the help of the advancements in support materials. In the proposed methods, the parts are first topologically optimized according to the defined conditions and then the machine codes are generated to have the interior of them constructed with shell like structures. These steps are done in an automated manner on Rhino3D (computer aided design software) and its algorithmic design tool Grasshopper3D. In order to prove the advantage of the proposed method, simply supported beams are manufactured via different approaches and tested under load. According to the results of the tests, the proposed approach has much better weight-strength performance.
\end{abstract}

\section{GİRIŞ̧ (INTRODUCTION)}

3 Boyutlu (3B) yazıcılar ile üretim ya da eklemeli imalat temel olarak nesnelerin katmanlar halinde üretilmesi prensibine dayanmaktadır. Geleneksel boşaltmalı imalat yöntemlerinde karşılaşan birçok sorun nispeten yeni olan eklemeli imalat yaklaşımlarıyla giderilmiştir. Karışık geometrilere sahip nesneler, kafes yapılar, çoklu malzemeye sahip nesneler, vb. eklemeli imalat ile rahatlıkla üretilebilmektedir [1]. Tasarım aşamasına getirmiş olduğu bu özgürlüklerden dolayı eklemeli imalat yöntemleri tasarım mühendisleri arasında oldukça ilgi görmektedir. Özellikle topoloji optimizasyonu eklemeli imalat yöntemlerinin yaygınlaşmasıyla (karmaşık geometrilerin üretilebilirliklerinin artmasıyla) daha da önemli duruma 
gelmiştir [2]. Topoloji optimizasyonu yöntemlerinin bu kadar önemli olmasının en temel nedeni parçaların mekanik özelliklerinde kötüleşmeye neden olmadan onları hafifletebilmeleridir. Günümüzde özellikle savunma ve havacılık endüstrilerinde yaygın olarak kullanılmaktadır.

Çalışma çerçevesinde geliştirilen yöntemde girdi olarak verilen parçaların yüklerine ve bağlantı noktalarına göre topoloji optimizasyonu yapılmaktadır. Sonrasında elde edilen yeni geometrinin eklemeli imalat yöntemlerinden olan Eriyik Yığma Modelleme (EYM) ile üretilebilmesi için üretim dosyası (G-kodları) üretilmektedir. Geleneksel yaklaşımlardan farklı olarak EYM sistemlerinin kafa yörüngesi dış profilin kabuklarından oluşmaktadır. Bu yeni yaklaşımla birlikte parçaların başarımları arttırılmaktadır.

Makalenin kalan bölümleri şu şekilde düzenlenmiştir. Takip eden bölümde çalışma ile yakından ilgili bilimsel yayınlarda örnekler verilerek değerlendirmeler yapılmıştır. Üçüncü bölümde önerilen yöntemin ayrıntıları açıklanmıştır ve sonrasında yöntem ile üretilen parçaların test sonuçları dördüncü bölümde paylaşılmıştır. Son bölümde sonuçlar tartışılmış ve ileride yapılması planlanan çalışmalar belirtilmiştir.

\section{2. İLGILİ LITERATÜR (RELATED LITERATURE)}

Günümüzde farklı eklemeli imalat yöntemleri, getirmiş oldukları üstün özelliklerden dolayı, topoloji optimizasyonu yapılmış parçaların üretiminde sıklıkla kullanılmaktadır. Bu yöntemler arasında en çok kullanılanı toz yatağı tabanlı yaklaşımlardır. Bu sistemlerin tercih edilmelerinin ana nedenleri farklı malzemeler (plastik, metal, seramik, vb.) işleyebilmeleri ve özel destek yapılarına ihtiyaç duymamalarıdır. EYM [3] ise son yıllarda, patent süresinin sona ermesi, makinelerin ucuzlaması ve farklı konfigürasyonlarının oluşmasıyla birlikte topoloji optimizasyonu yoğunlukla çalışılmaya başlanmıştır. $\mathrm{Bu}$ çalışmalarda daha çok parçaların iç yapılarının [4] ve destek yapılarının [5] optimizasyonlarına ağırlık verilmiştir. Mukavemeti yüksek malzemelerin (ABS Plus, PC ve Onyx) ve özel destek yapısı malzemelerinin (PVA) geliştirilmesi ile birlikte ilerleyen yıllarda EYM yönteminin topoloji optimizasyonu yapılmış parçaların üretiminde daha fazla kullanılması beklenmektedir.

İlgili literatürde eklemeli imalat ile uygulanan farklı topoloji optimizasyonu yöntemleri bulunmaktadır [6]. Cezalı Katı Eş Yönlü Malzeme (Solid Isotropic Material with Penalization, SIMP) [7] yöntemi günümüzde en yaygın olarak kullanılan yöntemlerden birisidir. Bu yöntemde daha önceden sonlu elemanlara ayrılmış olan parçanın elemanlar bazında ne kadar yoğunluğa sahip olması gerektiği literatürde sıklıkla kullanılan Sonlu Elemanlar Analizi (Finite Element Analysis, FEA) [8] sonucunda belirlenmektedir. Ceza katsayısının 1 'den büyük olmasıyla birlikte düşük yoğunluğa sahip olan elemanlar birkaç yineleme sonrasında 0 yoğunluğuna sahip olmaktadır. Yinelemeler tamamlandığında parça içerisinde sadece 0 ve 1 yoğunluğuna sahip sonlu elemanlar kalmaktadır. 1 ile ifade edilen elemanlar optimize edilen parçayı temsil etmektedir. Literatürde öne çıkan diğer bir yöntem ise kiriş tabanlı yapılar için özellikle geliştirilen Zemin Yapıları Yöntemidir [9]. Yüksek kiriş yoğunluğuna sahip bir yapı yöntemin uygulanmasıyla birlikte sadeleşmekte ve aynı zamanda istenen başarımı göstermektedir. Bahsedilen iki yöntemden tamamen farklı olan diğer yöntemlerde evrimsel algoritmalar kullanılarak parçaların topolojileri gereksinimlere göre iyileştirilmektedir. $\mathrm{Bu}$ yöntemler hem kirişli [10] hem de katı yapılara [11] uygulanabilmektedir. Literatürde çeşitli sürümleri bulunan topoloji optimizasyonu yöntemleriyle birlikte parçaların farklı mekanik özellikleri geleneksel üretim yöntemleri uygulandığında ortaya çıkan parçalara göre arttırılmaktadır.

\section{YÖNTEM (METHODOLOGY)}

Çalışma kapsamında topoloji optimizasyonu yapılmış parçaların üretimi için önerilen yöntemin akışı baştan sona kadar Şekil 1'de verilmiştir. Parçaların optimizasyonu yapıldıktan sonra iç yapılarını özel olarak üreterek dayanımlarını arttırmayı amaçlayan yöntem, şimdilik 2.5 boyutlu (2.5B) diye tabir edilen 2 boyutlu (2B) çizimlere derinlik kazandırılmasıyla elde edilen parçalara uygulanabilmektedir. İlerleyen çalışmalarda yaklaşımın daha karmaşık yapılara sahip 3 boyutlu (3B) nesneler üzerinde de uygulanabilmesi sağlanacaktır. Böylelikle kullanım alanının yaygınlaştırılması mümkün olacaktır. 
Şekil 1'de gösterilen tasarım ve üretim akışı Şekil 2'de sunulan örnek parça üzerinde uygulanmıştır. Kuvvet ve geometrik ölçülerin önemi olmadığı için şekil üzerinde gösterilmemiştir. Bu parçaya topoloji optimizasyonu yapılmadan üst orta noktadan kuvvet uygulandığı durumda yapılan sonlu elemanlar analizinin sonucu (gerilim dağılımı) Şekil 3'te gösterilmiştir. Sonuçtan anlaşılacağı üzere parçanın büyük bir bölümü fazla yüke maruz kalmamaktadır. Topoloji optimizasyonunun yapılmasıyla birlikte daha az malzeme ile aynı yükün taşınması mümkün olacaktır.

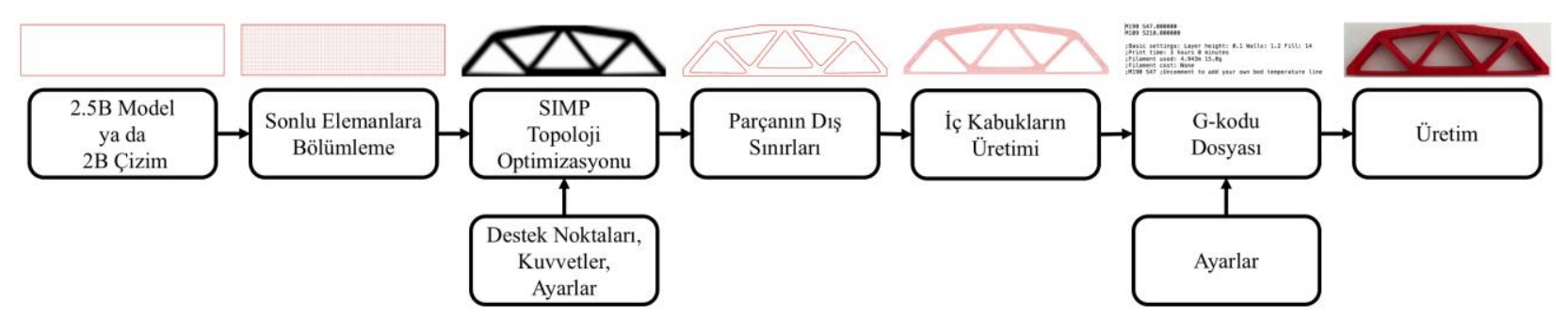

Şekil 1. Önerilen tasarım ve üretim akışı.

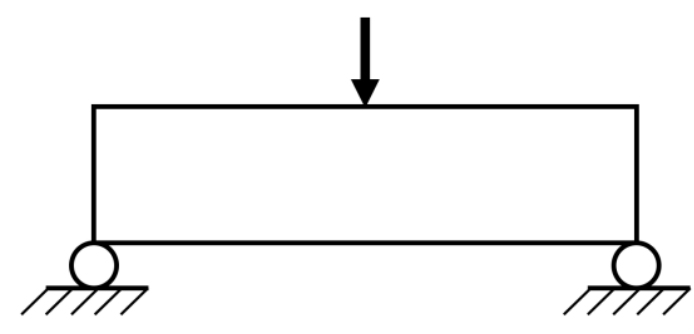

Şekil 2. Test parçası.

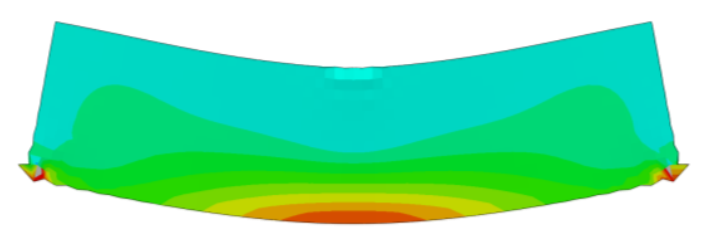

Şekil 3. Test parçasının sonlu elemanlar analiz sonucu.

Önerilen tasarım ve üretim akışı, 2.5B modelin ya da 2B çizimin akışa girdi olarak verilmesiyle birlikte başlar. İlk gerçekleştirilen işlem modelin önceden belirlenen boyutta sonlu elemanlara bölümlenmesidir. Optimizasyonun daha hassas gerçekleştirilmesi isteniyorsa sonlu elemanların boyutlarının oldukça düşük olması gerekmektedir. Örnek uygulamadaki dikdörtgen parçanın boyutları $120 \times 30 \times 10 \mathrm{~mm}^{3}$ iken sonlu eleman sayısı 3600 'dür $\left(120 \times 30 \mathrm{~mm}^{2}\right)$ ve sonlu elemanların boyutu $1 \times 1 \mathrm{~mm}^{2}$ 'dir. Hassasiyetin değil de hesaplama zamanının önemli olduğu durumlarda sonlu elemanların boyutları arttırılarak hesaplama süresi düşürülebilir. Böyle bir durumda ortaya çıkan parçanın üretilebilirliğini arttırmak için dış kabukta düzeltmeler yapılması gerekebilir. Parçanın bölümlenmesinden sonra Şekil 2'de tanımlanan destek yapıları, uygulanan kuvvet ve diğer gerekli ayarlar akışa girilir. Yapılan bu düzenleme sonrasında SIMP topoloji optimizasyon yaklaşımı parçaya uygulanarak optimize edilmiş parçanın dış sınırları belirlenir. Optimize edilmiş parçanın sonlu elemanlar analizinin sonucu (gerilim dağılımı) Şekil 4'te verilmiştir. Şekil 3'teki sonuç ile karşılaştırıldığında ciddi oranda malzemenin azıldığı gözlemlenmektedir. Topoloji optimizasyonu için seçilen yöntemin ayrıntıları takip eden alt bölümde açıklanmıştır. Parçanın dış sınırları elde edildikten sonra çalışmanın en önemli katkılarından olan kabuklu iç yapılar üretilir. Detaylı görünümü Şekil 5'te verilen bu iç yapılar ile birlikte topoloji optimizasyonu yapılmış parçaların mukavemetinin arttırılması 
amaçlanmıştır. Kabuk yapılar oluşturulurken Angus Johnson'ın [10] geliştirmiş olduğu Çokgen Öteleme Algoritması kullanılmıştır. Bu algoritmanın diğer benzer algoritmalara göre temel avantajı, adalı çokgenlerde başarıyla ötelenmiş yeni çokgenler oluşturabilmesidir. Dış sınırların ve iç kabuk yapılarının oluşturulmasının ardından üretimin yapılabilmesi için gerekli olan G-kodu dosyası, kullanılacak olan 3B yazıcıya özel olarak geliştirilmiş bir modül yardımıyla üretilir. Python programlama dili kullanılarak geliştirilen bu modül ile ilgili ayrıntılı bilgiler takip eden alt bölümlerde verilmiştir. G-kodu dosyasının üretilmesiyle birlikte üretim için dosya 3B yazıcıya aktarılıp parça üretilir. Kullanılacak olan 3B yazıcıya ve katman kalınlığına göre gerekli ayarların G-kodu dosyası üretimi öncesinde yapılması gerekmektedir.

Takip eden alt bölümlerde yöntemin önemli noktaları üzerinde durulmuştur.

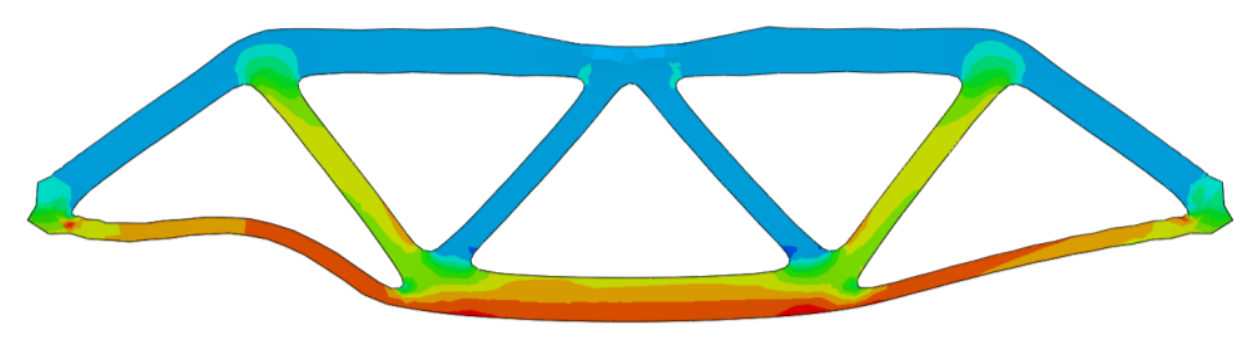

Şekil 4. Topoloji optimizasyonu yapılmış test parçasının sonlu elemanlar analiz sonucu.

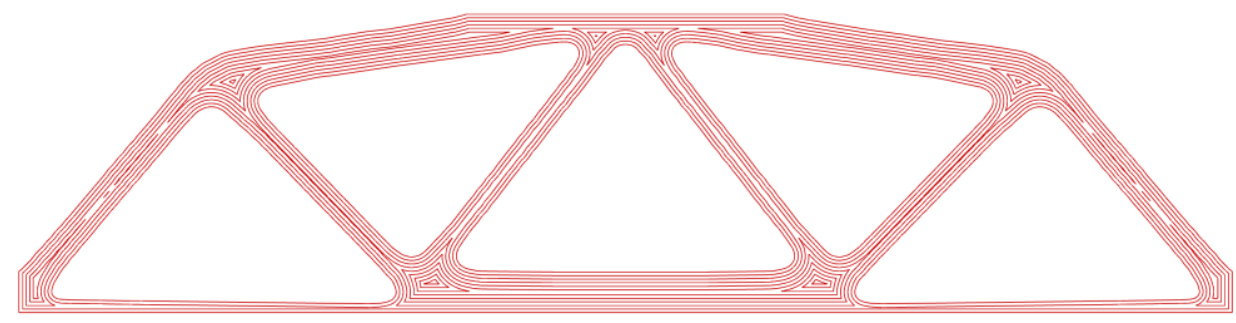

Şekil 5. Kabuklu iç yapılar.

\subsection{SIMP topoloji optimizasyonu}

Yöntem içerisinde kullanılan SIMP topoloji optimizasyonu yaklaşımı, yoğunluk tabanlı optimizasyon çözümleri arasında yer almaktadır. Literatürde çok farklı optimizasyon yöntemi bulunmaktadır. SIMP'nin özellikle seçilmesinin nedeni yöntemin Grasshopper3D ortamında gerçekleştirilmesi ve bu platform için sağlanan SIMP kaynakların güvenilir olmasıdır.

SIMP topoloji optimizasyon yönteminde temel amaç Denklem 3.1'de gösterildiği gibi sonlu elemanlara bölünen parçanın ( $n$ adet) elemanlarının yoğunluklarını $(\boldsymbol{\rho})$ bulmaktır. Bunu gerçekleştirirken elemanların yer değiştirme miktarlarını $(\boldsymbol{u})$ kullanmaktadır.

$$
\boldsymbol{\rho}=\left(\rho_{1}, \rho_{2}, \cdots, \rho_{n}\right)^{T}, \boldsymbol{u}
$$

Sonlu elemanların yoğunlukları parçanın genel uyumunu $(C)$ azaltacak şekilde düzenlenmektedir (Denklem 3.2 ve 3.3$)$.

$$
\begin{aligned}
& C=\boldsymbol{u}^{T} \boldsymbol{K}(\boldsymbol{\rho}) \boldsymbol{u} \\
& \boldsymbol{K}(\boldsymbol{\rho}) \boldsymbol{u}=\boldsymbol{f}
\end{aligned}
$$

Bu denklemlerde $\boldsymbol{K}$ evrensel sertlik matrisi olup $\boldsymbol{f}$ ise parçaya uygulanan dış kuvvetleri temsil etmektedir. Evrensel sertlik matrisi ayrıntılı olarak Denklem 3.4 ile ifade edilmektedir.

$$
\boldsymbol{K}=\sum_{i=1}^{n} \rho_{i}^{p} \boldsymbol{K}_{0}
$$


Denklem 3.4'te $\boldsymbol{K}_{0}$ yoğunluğu 1 olan sonlu elemanın sertlik matrisini ifade etmektedir. $p$ üssü ise cezalandırma katsayısını belirtmektedir. Bu katsayı 1 olduğunda optimizasyon sonucunda ortaya çıan sonlu elemanlar ara yoğunluk (0-1) değerlerine sahip olabilmektedir. Çalışmada olduğu gibi 1'den büyük olarak seçildiğinde optimizasyon sonrasında sadece 0 ve 1 yoğunluk değerlerine sahip sonlu elemanlar bulunmaktadır. 0 yoğunluğuna sahip elemanlar silinerek optimize edilmiş geometri elde edilmektedir.

\subsection{Yöntemin gerçekleştirilmesi}

Önerilen yöntem Rhino3D (bilgisayar destekli tasarım yazılımı) için özel olarak geliştirilmiş algoritmik modelleme yazılımı olan Grasshopper3D aracılığıyla gerçekleştirilmiştir. Bu yazılımda farklı geometriler üzerinde işlemler yapılabilmesi için bloklar bulunmaktadır. Bloklara gerekli girdiler sağlandıktan sonra işlem blok tarafından gerçekleştirilmekte ve sonuçları takip eden bloklara aktarılmaktadır. Algoritma geliştirmenin nispeten kolay olduğu bu yazılım ortamında kullanıcının ihtiyacı olan blokların bulunmaması durumunda kullanıcı tarafından farklı dillerde $(\mathrm{C}, \mathrm{C}++, \mathrm{C} \#$ ve Python) bloklar geliştirilebilmektedir. Çalışmada önerilen yöntem için geliştirilen Grasshopper3D akışı Şekil 6'da sunulmuştur.

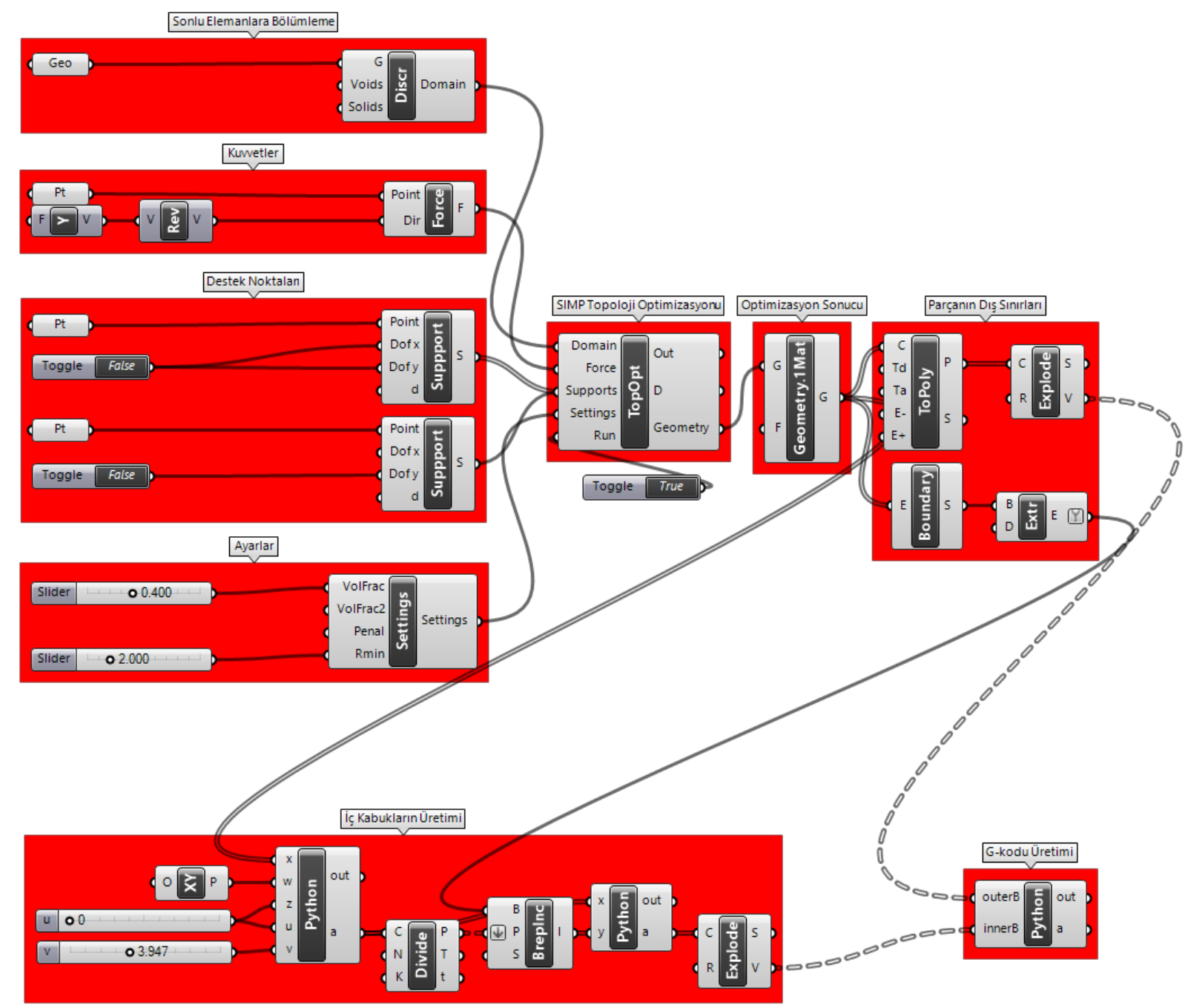

Şekil 6. Yöntemin Grasshopper3D uygulamast.

En sol tarafta bulunan bloklar yardımıyla SIMP yöntemi için gerekli girdiler (sonlu elemanlara bölümleme, uygulanan kuvvetler, destek noktaları ve diğer ayarlar) hazırlanmaktadır [13]. Sonrasında SIMP yöntemi 
koşturulmakta ve optimizasyon sonuçları elde edilmektedir. Yeni geometrinin diş sınırları elde edildikten sonra iç kabukların üretilmesine geçilmektedir. Kabuk üretiminde Grasshopper3D'nin sunduğu bloklar yetersiz olduğu için Python dilinde yazılarak iki yeni blok geliştirilmiştir. Bu bloklar yardımıyla yeni geometrinin içini dolduracak sayıda kabuk üretilebilmiş ve G-kodu dosyası çıkarılabilecek formata getirilmiştir. Son blok olan G-kodu üretimine girdi olarak dış profil ve iç kabukların bilgileri verilmektedir. $\mathrm{Bu}$ bilgiler ve kullanılan 3B yazıcıya özel değişkenler kullanılarak ilgili G-kodlarını içeren dosya otomatik olarak üretilmektedir. Parçalar 2.5B olduğu için katmanların yörüngeleri arasında bir farklılık bulunmamaktadır. Sonrasında üretilen dosya 3B yazıcıya aktarılarak üretim gerçekleştirilmektedir.

\subsection{Farklı örnek parçalar}

Önerilen yöntemin esnekliğini ve işlevselliğini göstermek amacıyla yöntem farklı özelliklere sahip parçalar üzerinde de uygulanmıştır. Askıya benzeyen ilk parçanın optimizasyon öncesi ve sonrası Şekil 7`de gösterilmiştir. Oluşturulan yörüngenin ayrıntısı da yine aynı şekilde verilmiştir. Görüldüğü üzere kabuk yapılar sorunsuz bir şekilde üretilmiştir. Diğer bir örnekte ise literatürde sıklıkla sınanan ankastre kiriş (Şekil 8) kullanılmıştır. Bir önceki örnekte olduğu gibi kuvvet elemanın uç noktasından uygulanmıştır. Geliştirilen yöntem herhangi bir 2.5B parçanın optimizasyonu yapmakta ve kabuklu üretim için otomatik olarak üretim dosyasını oluşturmaktadır.

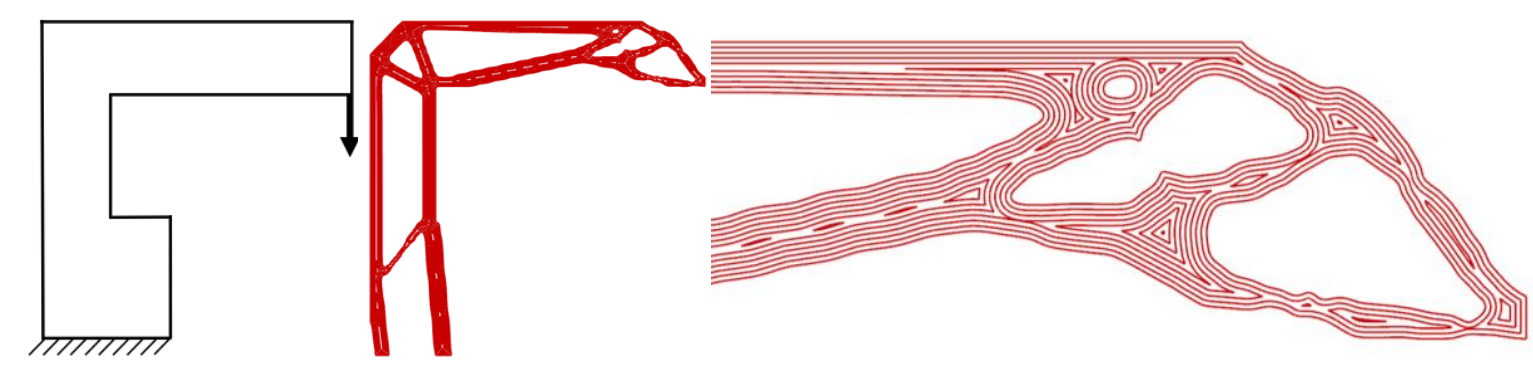

Şekil 7. Askı parçasının optimizasyonu
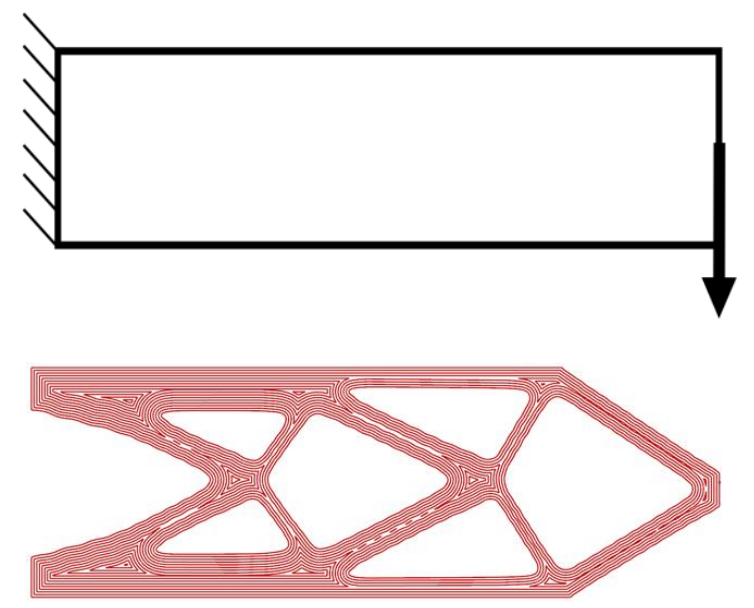

Şekil 8. Ankastre kirişin optimizasyonu

\section{TESTLER (TESTS)}

Önerilen yöntem kullanılarak üretilen basit dayanaklı kirişler ve karş1laştırma için Cura yazılımıyla üretilen kirişler Şekil 9'da gösterildiği gibi orta noktalarından yüklenerek test edilmişlerdir. Testler sırasından uygulanan kuvvet ve kafanın hareketi sürekli olarak kayıt edilmiştir. 5 farklı parça üzerinde yapılan testlerin 
sonuçları Şekil 10'da yer alan Kuvvet-Yer Değiştirme grafiğinde gösterilmiştir. Çapraz Iç̧ Yapı olarak tabir edilen parçanın G-kodu dosyası geleneksel akış içerisinde kullanılan Cura yazılımı ile üretilmiştir ve parçanın iç yapısı çapraz ağlardan oluşmaktadır. Kabuklu İç Yapı-Cura 1-2 olarak isimlendirilen parçalar birebir aynı olup yine Cura yazılımıyla üretilmişlerdir. İlk parçadan farklılıkları çapraz iç yapılar yerine, yöntemde de kullanıldığı üzere, kabuk yapılara sahip olmalarıdır. Test edilen son iki parçanın (Kabuklu $\dot{I} c ̧$ Yapı - Cura 3-4) G-kodu dosyaları geliştirilen Grasshopper3D akışıyla üretilmiş ve parçalar bu dosyalar kullanılarak 3B yazıcı ile üretilmiştir. Şekil 10'da sunulan sonuçlar incelendiğinde geliştirilen yöntem ile üretilen parçaların daha fazla yüke $(\sim 2600 \mathrm{~N})$ dayanabildiği görülmektedir.

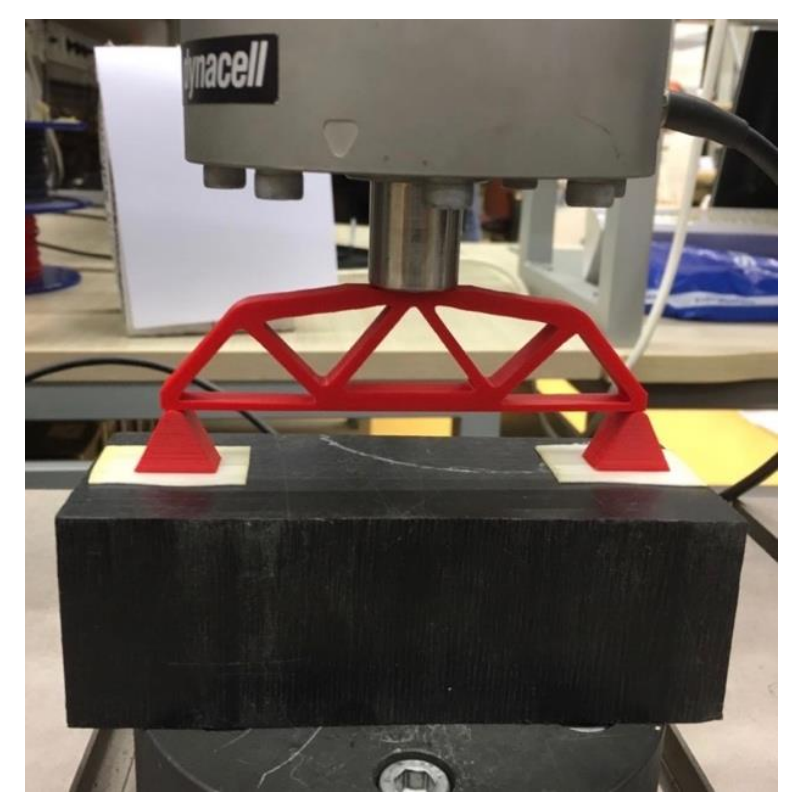

Şekil 9. Yükleme testi.

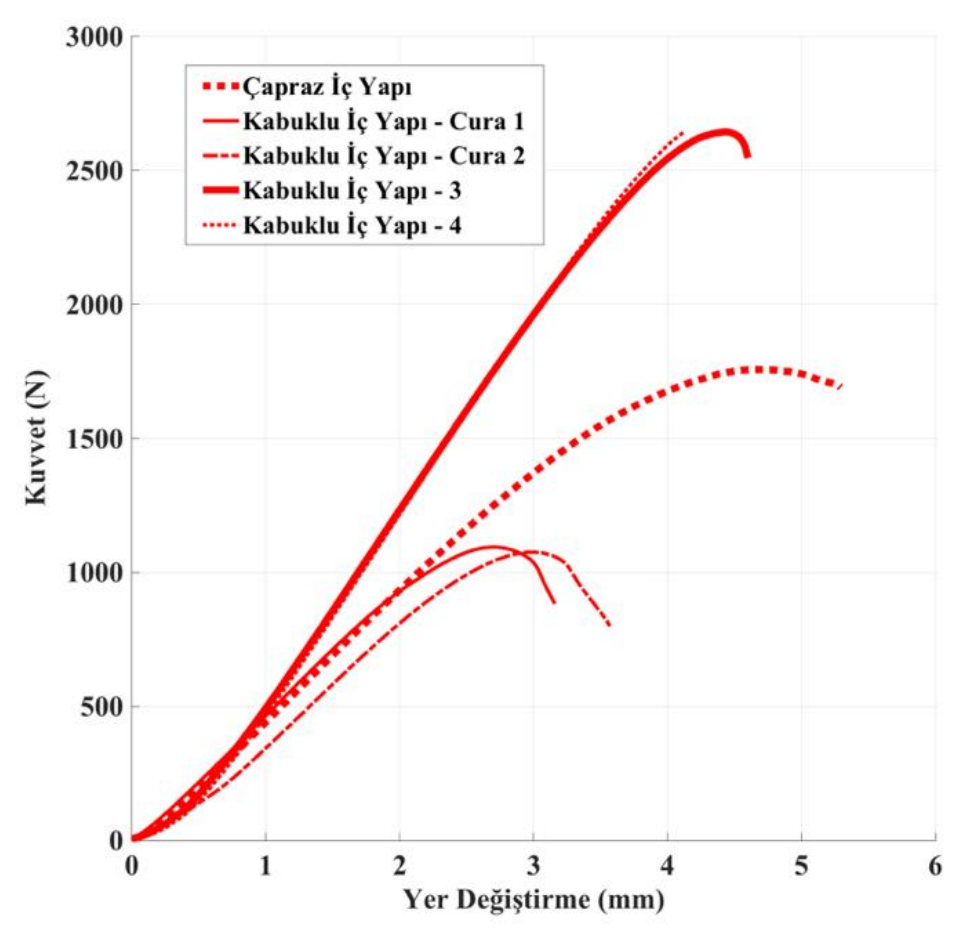

Şekil 10. Yükleme noktasındaki Kuvvet - Yer Değiştirme grafikleri. 
Parça kütlerinin yük taşıma kapasitesine olan etkisini görmek için, Tablo 1'de sunulduğu üzere, parçaların taşıyabildikleri yük değerler kütlelerine bölünerek bir oran elde edilmiştir. Tablonun dördüncü kolonunda sunulan değerler incelendiğinde önerilen yöntemle üretimi gerçekleştirilen test parçalarının daha başarılı olduğu görülmektedir. Parçaların nihai üretim dosyalarının çıkarılması için geçen süreler de Tablonun son kolonuna eklenmiştir. Önerilen yöntem komutların üretilmesi için daha fazla süreye ihtiyaç duymaktadır. Bunun temel nedeni algoritma bir ticari yazılım içerisinde geliştirilmiştir ve doğrudan çalışmamaktadır. Yaklaşımın tamamı $\mathrm{C}++$ ya da Python programlama dilleriyle geliştirilirse Cura yazılımından daha kısa sürede komut dosyalarını oluşturacaktır. Sürelerden çıkarılacak diğer bir nokta ise kabuk yörüngelerin oluşturulması için geçen sürenin çapraz yörüngelerin oluşturulması için gereken süreden daha fazla olduğudur. Kabuklar için özel algoritmalar kullanıldığından sürenin fazla olması beklenen bir durumdur.

Tablo 1. Üretilen Parçaların Ă̈ırlıkları

\begin{tabular}{|l|c|c|c|c|}
\hline Model & Kütle (g) & En Fazla Yük (N) & Oran (N/g) & Süre (s) \\
\hline Çapraz İç Yap1 & 13,9493 & 1757 & 125,96 & 13,96 \\
\hline Kabuklu İç Yap1 - Cura 1 & 13,3041 & 1095 & 82,31 & 16,35 \\
\hline Kabuklu İç Yap1 - Cura 2 & 13,2598 & 1075 & 81,07 & 16,35 \\
\hline Kabuklu İç Yap1-3 & 17,6232 & 2643 & 149,98 & 21,55 \\
\hline Kabuklu İç Yap1 - 4 & 17,5927 & 2644 & 150,29 & 21,55 \\
\hline
\end{tabular}

\section{SONUÇ (CONCLUSION)}

$\mathrm{Bu}$ çalışmada geliştirilen ve gerçekleştirilen yöntem ile girdi olarak verilen mekanik parçaların topolojileri optimize edilmekte ve FDM yöntemi ile üretilmeleri durumunda optimize edilmiş parçanın iç yapısı kabuklardan oluşacak şekilde nozul kafasının hareket yörüngeleri otomatik olarak oluşturulmaktadır. Gerçekleştirilen mekanik testler sonucunda önerilen tasarım ve üretim akışının geleneksel FDM üretim akışına göre daha iyi sonuçlar verdiği ortaya çıkmıştır. Parçaların yük taşıma kapasiteleri yaklaşık iki katına çıkmıştır.

Takip eden çalışmalarda önerilen çalışmanın

- 3B parçalar için de uygulanabilmesi,

- Farklı eklemeli imalat işlemleri ile kullanılabilmesi

- Farklı özelliklere (daha kırılgan, daha sünek, vb.) sahip malzemeler üzerindeki başarımı

için araştırmalar yürütülecektir.

\section{KAYNAKLAR (REFERENCES)}

[1] I. Gibson, D. Rosen, B. Stucker, Additive Manufacturing Technologies, Springer, New York, 2015.

[2] B. Aktimur, E. Gökpınar, Katmanlı Üretimin Havacılıktaki Uygulamaları, Gazi Üniversitesi Fen Bilimleri Dergisi Part C: Tasarım ve Teknoloji 3 (2014) 463-469.

[3] R. Rezaie, Topology optimization for fused deposition modeling process, Procedia CIRP 6 (2013) 521-526.

[4] N. Gardan, A. Schneider, Topological optimization of internal patterns and support in additive manufacturing, Journal of Manufacturing Systems 37 (2015) 417-425. 
[5] M. Langelaar, Topology optimization of 3D self-supporting structures for additive manufacturing, Additive Manufacturing 12 (2016) 60-70.

[6] Z. Tomás, G.H. Paulino, Bridging topology optimization and additive manufacturing, Structural and Multidisciplinary Optimization 53.1 (2016) 175-192.

[7] M.P. Bendsøe, O. Sigmund, Material interpolation schemes in topology optimization, Archive of applied mechanics 69.9-10 (1999) 635-654.

[8] E. Esener, E. Sönmez, M. Furat, Metal Şekillendirme Proseslerinde Sac Açınım Geometrisinin Sonlu Elemanlar Yöntemi ile Geliştirilmesi, Gazi Üniversitesi Fen Bilimleri Dergisi Part C: Tasarım ve Teknoloji 6 (2018) 79-89.

[9] M.P. Bendsøe, A. Ben-Tal, J. Zowe, Optimization methods for truss geometry and topology design, Structural optimization 7.3 (1994) 141-159.

[10] H. Kawamura, H. Ohmori, N. Kito. Truss topology optimization by a modified genetic algorithm, Structural and Multidisciplinary Optimization 23.6 (2002) 467-473.

[11] S.Y. Wang, K. Tai, Structural topology design optimization using genetic algorithms with a bit-array representation, Computer methods in applied mechanics and engineering 194.36-38 (2005) 37493770 .

[12] A. Johnson, Clipper-an open source freeware library for clipping and offsetting lines and polygons, http://www.angusj.com/delphi/clipper.php, 2018. Erişim Tarihi: 22 Temmuz 2018.

[13] TopOpt plugin for Rhino and Grasshopper, http://www.topopt.mek.dtu.dk/Apps-andsoftware/TopOpt-plugin-for-Rhino-and-Grasshopper, 2018. Erişim Tarihi: 25 Kasım 2018. 